\title{
Pesquisa em Turismo no Brasil: uma Revolução Silenciosa?
}

\author{
Tourism Research in Brazil: a Silent Revolution?
}

\author{
Sérgio Rodrigues Leal (LEAL, S. R.) ${ }^{1}$
}

RESUMO - O texto aborda os desenvolvimentos recentes da Pesquisa em Turismo no Brasil com foco em algumas das questões que levam à pergunta do título deste artigo de opinião. São comentadas as questões ligadas ao fortalecimento das bases de conhecimento em turismo, ao amadurecimento da ANPTUR - Associação Nacional de Pesquisa e Pós-Graduação em Turismo, à inserção de pesquisadores brasileiros na academia internacional e à consolidação de periódicos científicos em turismo no Brasil.

Palavras-chave: Pesquisa em Turismo; Produção de Conhecimento em Turismo; PósGraduação em Turismo.

\begin{abstract}
The text addresses the current advances in Tourism Research in Brazil with an emphasis on some of the issues that led to the question in the title of this opinion paper. Issues related to the strengthening of a tourism knowledge basis, to the maturation of ANPTUR - the National Association of Tourism Research and Postgraduate Education, to the active participation of Brazilian researchers in the international academy and to the consolidation of academic journals in tourism in Brazil are commented.
\end{abstract}

Key words: Tourism Research; Knowledge Production in Tourism; Postgraduate Studies in Tourism

\footnotetext{
${ }^{1}$ Membro do Comitê Científico da Revista Turismo e Sociedade desde 21 de dezembro de 2010. Formação: Graduação em Turismo com MBA em Administração de Marketing de Serviços pela Universidade Federal de Pernambuco (UFPE), Mestrado em Turismo pela Universidade James Cook (Austrália) e Doutorado em Turismo pela Universidade de Surrey (Reino Unido). Professor da Universidade Federal do Rio Grande do Norte (UFRN) - Departamento de Turismo e Programa de PósGraduação em Turismo. Endereço: Universidade Federal do Rio Grande do Norte (UFRN) Departamento de Turismo - Campus Lagoa Nova. CEP: 59.072-970 - Natal - Rio Grande do Norte (Brasil). Telefone/Fax: (84) 3215-3535. E-mail: sleal@ufrnet.br
} 
A educação em turismo no Brasil, com especial ênfase no nível da pósgraduação stricto sensu, vem vivendo um momento especial. O fortalecimento das bases de conhecimento, o amadurecimento da associação de programas de pós-graduação, a inserção internacional de pesquisadores e a consolidação de periódicos científicos são algumas das pistas que levam a crer que a pesquisa em turismo no Brasil vem crescendo não só quantitativa mas, também, qualitativamente desde o início do século atual.

O fortalecimento das bases de conhecimento é perceptível através da profundidade dos livros e artigos publicados. Diferentemente do fim da década de 1990, quando o crescimento do número de cursos e alunos de graduação em turismo estimulava a publicação de material didático em grande quantidade, a produção atual busca mais profundidade e maior especialização de temas relevantes para a área. No lugar dos livros introdutórios de turismo e de hotelaria ou das coletâneas de trabalhos apresentados em congressos, por exemplo, vê-se livros sobre temas mais densos, como a filosofia do turismo (PANOSSO NETTO, 2005) e a relação da antropologia com o turismo (GRABURN et al., 2009), entre diversos outros. Observa-se, ainda, uma tendência de tradução de livros de autores consagrados, como Pearce (2003) Airey \& Tribe (2008), Veal (2011), entre outros. A criação de grupos de pesquisa e de eventos acadêmicos para tratar de aspectos relacionados ao estudo crítico do turismo também demonstra o nível de maturidade que a produção do conhecimento em turismo no país vem conquistando.

O amadurecimento da Associação Nacional de Pesquisa e Pós-Graduação em Turismo (ANPTUR), que começou a promover, em $2005^{2}$, um seminário anual que congrega os principais pesquisadores do turismo nacional bem como professores e pesquisadores de todas as regiões do país, foi um marco para a consolidação da pesquisa em turismo no Brasil. Em 2007, a ANPTUR deu início à publicação da Revista Brasileira de Pesquisa em Turismo, um importante veículo para a disseminação do conhecimento científico na área. Assim, através destas iniciativas, pesquisadores dos Programas de Turismo e áreas correlatas têm dois excelentes canais de comunicação com a comunidade acadêmica de turismo nacional.

\footnotetext{
${ }^{2}$ Embora uma primeira edição do Seminário da ANPTUR tenha acontecido em 2002, foi apenas a partir da segunda edição, em 2005, que o evento passou a ser anual e contou com a apresentação de trabalhos e passou a servir como ponto de encontro e debate dos pesquisadores nacionais.
} 
Outro fato marcante para a possível Revolução Silenciosa foi a inserção de pesquisadores brasileiros na comunidade acadêmica internacional. Alunos de mestrado e de doutorado, bem como pesquisadores realizando investigações de pós-doutorado, geralmente contemplados com bolsas de estudos, tiveram a oportunidade de conviver com os seus pares internacionais. Isso vem trazendo resultados ao longo dos últimos anos, quando pesquisadores internacionais de renome passaram a proferir palestras em eventos no Brasil bem como publicar textos em parceria com pesquisadores nacionais muitas vezes seus alunos e/ou ex-alunos. A importância que este tema ganhou pôde ser constatada no Seminário da ANPTUR 2010, quando a mesa de encerramento do evento foi composta por professores de instituições de países como Austrália, Finlândia, Espanha, Portugal e Reino Unido.

Por fim, percebe-se que, embora o número de periódicos científicos em turismo no país tenha diminuído, aqueles que permanecem em circulação vêm se firmando como importantes instrumentos de disseminação do conhecimento científico produzido na área. O estímulo da CAPES (Coordenação de Aperfeiçoamento de Pessoal de Nível Superior) à publicação em periódicos fez com que professores e alunos, especialmente os da pós-graduação, priorizassem este meio para a divulgação dos resultados de suas pesquisas.

Por todas estas constatações é que se faz a pergunta - provocação - no título deste texto de opinião para a Revista Turismo e Sociedade. A pesquisa em turismo no Brasil não vive mais um momento como o dos anos 1990, com a repetição de idéias, de conceitos e de metodologias com o propósito de produzir (e vender) mais conhecimento científico na área. Ainda assim, percebe-se o crescimento contínuo da publicação dos resultados de estudos na área- através de livros, artigos e trabalhos apresentados em eventos. Espera-se que este crescimento seja mais qualitativo do que o de outrora e que assim desenvolva os frutos para uma revolução da Pesquisa em Turismo no Brasil nos próximos anos.

\section{REFERÊNCIAS}

AIREY, D.; TRIBE, J. (Org.). Educação Internacional em Turismo. São Paulo: SENAC/SP, 2008. 
GRABURN, N.; BARRETTO, M.; STEIL, C.; GRÜNEWALD, R.; SANTOS, R. Turismo e antropologia: Novas abordagens. Campinas, SP: Papirus, 2009.

PANOSSO NETTO, A. Filosofia do turismo: teoria e epistemologia. São Paulo: Aleph, 2005.

PEARCE, D. G. Geografia do Turismo: Fluxos e regiões no mercado de viagens. São Paulo: Aleph, 2003.

VEAL, A. J. Metodologia de pesquisa em lazer e turismo. São Paulo: Aleph, 2011. 